revista do ieb n 46 p. 179-199 fev 2008

\title{
La "Carta pras icamiabas": o la falta de carácter de un héroe imperial
}

Jerónimo Pizarro ${ }^{1}$

Resumo

Na segunda novela de Mário de Andrade, Macunaíma (1928), encontra-se uma carta muito singular e dissonante dirigida às icamiabas, ou mulheres amazonas, assinada pelo herói da saga, o "herói sem nenhum caráter". Transformado no Imperador da Selva Virgem, Macunaíma dirige a suas súditas uma carta na qual Andrade parodia o discurso escrito e a retórica pós-colonial das elites letradas nacionais. Esse texto epistolar pode ser lido produtivamente como um exemplo do tipo de "escrita" que "surge entre mimese e mímica", para dizê-lo com Homi Bhabha; de escrita que desafia a "intenção épica da missão civilizadora”. Dentro da novela-rapsódia de Andrade, a carta constitui, além disso, um momento da metamorfose do herói, a primeira de natureza lingüística, e uma entronização, isto é, um momento anterior ao destronamento carnavalesco.

Palavras-chave

Macunaima, Mário de Andrade, Carta pras icamiabas (ou amazonas), Modernismo brasileiro, imitação, paródia lingüística.

1 Harvard University / Universidade de Lisboa. 
revista do ieb n 46 p. 179-199 fev 2008

\title{
The "Letter to the Icamiabas": or the lack of character of an imperial hero
}

Jerónimo Pizarro

\begin{abstract}
In Mário de Andrade's second novel, Macunaima (1928), one comes across a very unique and dissonant letter addressed to the Icamiabas, or Amazon women; the letter is, signed by the hero of the saga, the "hero without any character". Transformed into the Emperor of the Virgin Jungle, Macunaíma addresses his subjects in a letter in which Andrade parodies the written discourse and postcolonial rhetoric of national lettered elites. That epistolary text might be constructively read as an example of the type of "writing" that "emerges between mimesis and mimicry", to say it with Homi Bhabha; a writing that defies the "the epic intention of the civilizing mission". In Andrade's novel-rhapsody, the letter constitutes, in addition, a moment of the hero's metamorphoses, the first of a linguistic nature, and an enthronization, that is to say, a moment previous to the carnivalesque desenthronization.
\end{abstract}

\section{Keywords}

Macunaima, Mário de Andrade, Letter to the Icamiabas (or Amazons), Brazilian Modernism, imitation, linguistic parody. 
En el capitulo IX de Macunaima, o herói sem nenhum caráter, se encuentra una carta dirigida a las icambiabas o amazonas. Se trata de un texto sorpresivo, disonante, que interrumpe el tono coloquial del relato y que, considerado en retrospectiva, vuelve menos creíble el origen mítico de la ficción: la oralidad. La carta difícilmente parece haber salido del "bico dourado" del "papagaio verde"2 que habría contado la historia al narrador; es decir, del papagayo que habría preservado del olvido las frases y los actos del héroe, transmitidos posteriormente por la tradición oral. Pero la contradicción es sólo aparente y se resuelve con imaginación: es sólo aparente, porque sabemos que el origen es mítico, no real; y se resuelve con imaginación, porque basta pensar en un papagayo letrado. De hecho, sabemos que Macunaima no habría sido posible sin muchas de las lecturas efectuadas por Mário de Andrade y que ese papagayo auriverde ${ }^{3}$ no se pudo nutrir, por lo tanto, sólo de sonidos. A este punto volveremos otras veces. Lo que conviene realzar ahora es la singularidad, casi escandalosa, de esa "Carta pras icamiabas", que debe menos a la tradición oral (o a las leyendas recogidas por Theodor Koch-Grünberg, por ejemplo) que a la escritura amanerada de muchos paulistas y, en general, de ciertas élites letradas. En ella, Andrade no busca reproducir una "fala impura", como en el resto de la novela, sino imitar el manierismo de esos paulistas que al intentar expresarse con purismo, con casta (de donde viene "castizamente") y sin hacer uso de barbarismos ni de voces extrañas, acentuaban una fractura lingüística entre lo escrito y lo hablado.

De hecho, la existencia de esa carta en Macunaima debe considerarse sospechosa, porque toda la novela o "rapsodia" - como la llamó Mário de Andrade, para destacar la oralidad - pretende dar al traste con ese empeño de purismo y de calco de la "lengua de Camões”, esto es, del portugués peninsular. Macunaima

2 ANDRADE, Mário de. Macunaima: o herói sem nenhum caráter. Telê Porto Ancona Lopez (Coord.). Madrid: ALLCA XX / Ediciones UNESCO, 1988. p. 168. (Colección Archivos, vol. 6).

3 Este papagayo tiene un carácter simbólico que se ve reforzado cuando nos enteramos de que "depois abriu asa rumo de Lisboa" (ANDRADE, Mário de. op.cit. p. 168. (Colección Archivos, vol. 6).). Los dos adjetivos (“dourado" y "verde") ilustran bien un propósito de Mário de Andrade: usar la adjetivación sólo en casos de rigor.

4 ANDRADE, Mário de. op. cit. p.168 
pertenece a una época en la que Andrade buscaba, aún con un impulso vanguardista, "forçar a nota do brasileirismo" ${ }^{5}$, como una manera nueva de explorar el mestizaje lingüístico. Por ello, la existencia de la carta provoca un choque y hace manifiesto un cambio de registro. Sólo que el choque se minimiza y el cambio no se revela tan drástico, en última instancia, porque a medida que la leemos y nos percatamos de su singularidad, también captamos que existe una intención lúdica. Sin ir más lejos, el título ("Carta pras icamiabas") ya contiene un llamado de atención acerca de la pureza de la dicción, pues el "pras” es coloquial. Ésta y otras marcas dejadas por Andrade en el texto epistolar permiten reconocer el enmascaramiento verbal. Así, es sobre todo interesante detenerse en aquellos pasos en los cuales el héroe, al intentar imitar un discurso sofisticado y culto, tropieza; porque esos deslices son pistas fundamentales. Son ese "tic" que denuncia al que no puede imitar totalmente un modelo; son esa desviación que, cuando es activa y no pasiva, propone un desafío y una diferencia. A este respecto, se puede evocar la imagen sugestiva que aprovecha Gilda de Mello e Souza6" "um tupí tangendo um alaúde" ("0 Trovador", Paulicéia desvairada). Si alargáramos la imagen a Macunaima y aceptáramos que la obra es una rapsodia tañida por un tupí, entonces - siempre a un nivel metafórico - podríamos imaginar que la carta a las mujeres amazonas es la rapsodia tañida por un letrado. Pero hay algo falso en la tonada. Resulta más la imitación de un candidato a letrado y no propiamente la de un letrado. En este sentido, la metamorfosis del héroe en un hombre de lenguaje afectado, le permite a Mário de Andrade, como diría Oswaldo de Andrade, la "absorção do inimigo sacro": "Perguntei a um homem o que era o Direito. Ele me respondeu que era a garantia do exercício da possibilidade. Esse homem chamava-se Galli Mathias. Comi-o."7

El objeto de este ensayo es reflexionar sobre la carta a las Amazonas - símbolo negativo de todas las conquistas sexuales del héroe - y sobre la idea de imitación que está implícita en la escritura del texto. Aunque Mário de Andrade consideraba que la lectura en clave "antropófaga" perjudicaba

5 ANDRADE, Mário de. Macunaíma: o herói sem nenhum caráter. Telê Porto Ancona Lopez (Coord.). Madrid: ALLCA XX / Ediciones UNESCO, 1988. p. 400. (Colección Archivos, vol. 6).

6 SOUZA, Gilda de Mello e . O tupi e o alaúde: uma interpretação de Macunaíma. São Paulo: Duas Cidades, 1979.

7 Manifiesto Antropófago, 1928. 
su libro, ya que había intentado algo audaz y único ${ }^{8}$, lo cierto es que en la carta "devora" el discurso de las élites letradas; y que al hacerlo, al plasmar la primera transformación del héroe que no pasa por su cuerpo, construye una máscara lingüística extremamente significativa. En el texto epistolar, Andrade recurre a una apropiación paródica que interrumpe el discurso "tupi-barroco-surreal" de toda la narración, recurso que, al acentuar determinados rasgos lingüísticos sobre otros, permite forjar una máscara para el protagonista. La carta tiene la originalidad de presentar ya no una transformación "externa" del Emperador de la Selva Virgen (Macunaima) - en forma de arpón o con ojos azules, por ejemplo -, sino una transformación “interna”, que se manifiesta a través del lenguaje. Utiliza un lenguaje imitativo que, por tener un trasfondo real, quiebra la idea de un tiempo mítico y fabuloso en el cual las acciones se desarrollan; un tiempo en el cual el héroe parece perseguir a las mujeres, como un Dios que persiguiera a una Dafne múltiple. En suma: el lenguaje de la carta es determinante porque introduce, como observó Roberto Schwarz ${ }^{10}$, la historia, que durante el modernismo brasileño, con la analogía del proceso digestivo, tendió a desvanecerse. Macunaíma ya no pretende ser todos los brasileños, sino un cierto brasileño. Y este contraste, provocado por la inclusión de la historia, es doblemente determinante, porque sucede en un libro en el que la geografía se desterritorializa y el cuerpo pierde su corporeidad ${ }^{11}$.

8 ANDRADE, Mário de. Macunaima: o herói sem nenhum caráter. Telê Porto Ancona Lopez (Coord.). Madrid: ALLCA XX / Ediciones UNESCO, 1988. p.400. (Colección Archivos, vol. 6).

9 Son palabras de Alfredo Bosi, citadas por Roberto Reis (REIS, Roberto. Passando a limpo. Ideologies and literature 2, 1, 1987. p. 137). Esto no desmiente el hecho de existir un esqueleto europeo, como diría Gilda de Mello e Souza, que sigue la tradición del Grial o de otras estructuras narrativas. Silviano Santiago (SANTIAGO, Silviano. Vale quanto pesa. Rio de Janeiro: Paz e Terra, 1982. p. 39) casi exalta este "silêncio do narrador-intelectual".

10 SCHWARZ, Roberto. Essays on brazilian culture. Londres: Verso, 1992. p. 9.

11 Aunque se queda en el elogio, puede ser útil consultar el ensayo influenciado por el Antiedipo de Deleuze-Guatarri de Gustavo Lespada (LESPADA, Gustavo. La metamorfosis y otras estrategias en Macunaima de Mário de Andrade. In: Esa promiscua escritura: estudios sobre literatura latinoamericana. Córdoba: Alción Ed., 2002. p. 69-91), sobre las transgresiones que contiene y provoca la obra de Andrade. 
En una carta de Mário de Andrade a Manuel Bandeira se puede advertir la doble recepción, adversa y elogiosa, que tuvo desde el comienzo la "Carta pras icamiabas":

Tenho me divertido é com o caso da "Carta". Você inda tem razão, não concordo mais tem, porque acha a carta besta, julga a carta em si. Acho graça mas é nesses que pretendem discutir a possibilidade da "Carta" num livro daqueles. Isso acho de uma besteira refinada. A carta é um intermezzo. Fatigante, intolerável pra uns, pra outros tem sido um gozo. Osvaldo [de Andrade] gosta muito dela. P[aulo] Prado também. [Antônio de] Alcântara [Machado] não tive tempo de perguntar, porém só agora [1928] leu o livro, estava escrevendo o Anchieta [na Capitania de São Vicente]. Ontem nos achamos: - Seu livro é maravilhoso. Não tive tempo pra perguntar nada. 0 Couto [de Barros], você é um safado, mande me contar se por acaso, falando no livro aí você não contou que não gostava da carta, diz que Prudentico [Prudente de Morais, neto], Rodriguinho [Rodrigo Melo Franco] também não gostam dela, estou imaginando uma sugestão que estou longe de imaginar qualquer intenção maldosa de você está claro. Pois o Couto, o que me falara foi da carta. Gostou muito e até só por atrapalhações não transcreveu parte dela no Diário [Nacional]. Foi pra aí e voltou também não gostando da "Carta" já antes gostada. Filho-daputei ele, ficou cheio de mãos, se borrou dizendo que gosta da carta em si, não do livro - o contrário de você. Tarsila [de Amaral] gosta da "Carta". Tou com vontade de fazer uma estatística. ${ }^{12}$

Más allá de las vacilaciones y las opiniones encontradas, llama la atención el que se haya tratado la carta por separado y que se la haya juzgado siempre por oposición al libro. Mário de Andrade la considera un intermezzo y, aunque trataría de no verla como un elemento aislado, en 1928 ya se habría pensado en una publicación parcial. Sin duda es un texto polémico y, como ya se dijo, disonante. El narrador-rapsoda cede su voz a Macunaíma, y la ambigüedad y densidad poética del texto (que "em estilo é poema"13) y la narrativa mítica del mismo, casi

12 ANDRADE, Mário de; BANDEIRA, Manuel. Correspondência. Marco Antonio de Moraes (Ed.). São Paulo: EDUSP/ IEB, 2000. p. 406. (Correspondência de Mário de Andrade).

13 Ibid. p. 424. 
desaparecen por completo ${ }^{14}$. El lenguaje se vuelve embrollado y pomposo, abundante en rodeos y dejos arcaicos. Le da a la saga folklórica una dimensión novelesca, pues pone de realce la heteroglosia que la antropofagia aprovecha, pero sin distinguir plenamente los diferentes niveles o registros ${ }^{15}$. Esto hace del "poema héroi-cômico"16 una sátira aún más incisiva y puntual que, mientras carnavaliza o parodia a gran parte de la sociedad ilustrada, también oculta su propia erudición. Si no fuera por la carta, Macunaíma se habría podido ajustar más al mito de haber sido una obra escrita en una hamaca, en el lapso de unos días, que a la realidad de semejar una obra erudita, o casi un pastiche, con resonancias de diversas crónicas etnográficas y composiciones populares. (De hecho, tal vez no contenga menos alusiones que un texto de Joyce o Borges.) Entre la selva y la escuela, como sugiere el "Manifiesto da Poesia Pau-Brasil" (1926), Mário de Andrade se inclina más por la selva; pero en la carta se da un giro, y el que habla está más del lado civilizado... Es como si hubiera optado, para usar la fórmula del otro manifiesto célebre, por not tupi.

Ahora bien, si los contemporáneos del autor no manifestaron una opinión unánime con respecto al capítulo IX, tampoco lo ha hecho la crítica más reciente, que lo ha interpretado de maneras diferentes. Jorge de Lima, que fue el único que le dedicó en 1929 mitad de un libro a Macunaima, muestra perplejidad, y escribe que la carta tiene "o encanto das historias de mãe-prêta e o pintoresco das coisas que um [Pedro Vaz de] Caminha contasse em carta às icamiabas da terra. Porque aquela carta em "estylo medico-purista" como lhe chama Tristão [de Athaíde ${ }^{17}$ ] é a unica paulificancia

14 Sobre los recursos poéticos de Mário de Andrade puede consultarse HELENA, Lucia. Mário e Oswald de Andrade: identidade e diferença. In: Uma literatura antropofágica. Rio de Janeiro: Liv. Ed. Cátedra, 1982. p. 73-94.

$15 C f$. "Quis escrever um livro em todos os linguajares regionais do Brasil. 0 resultado foi que, como já disseram, me fiz incompreensível até para os brasileiros". ANDRADE, Mário de. Macunaima: o herói sem nenhum caráter. Telê Porto Ancona Lopez (Coord.). Madrid: ALLCA XX / Ediciones UNESCO, 1988. p. 423. (Colección Archivos, vol. 6).

16 ANDRADE, Mário de. op.cit. p. 426.

17 Seudónimo de Alceu Amoroso Lima. El artículo citado apareció en 0 Jornal, el 9 de septiembre de 1928. Sobre la recepción de la obra, véase SANTIAGO, Silviano. História de um livro. In: Nas malhas da letra: ensayo. São Paulo: Companhia das Letras, 1989. p. 124-139. 
do livro"18. Por su parte, otros críticos como Cavalcanti Proença, consideran que la carta es la cuota o gravamen que los escritores brasileños debían pagar entonces, cuando intentaban, intencionalmente o no, escribir de otra manera, "em linguagem da sua terra"19. Y señala, asimismo, muchas de las incorrecciones o vacilaciones ortográficas del texto; su confusión de tiempos verbales y palabras semejantes que producen un efecto cómico; y la mezcla de vocablos populares en medio de expresiones (o casi períodos enteros de frases) cultas y filopuristas.

En la década de los 70, Haroldo de Campos publica su Morfología do Macunaima ${ }^{20}$, que propone una lectura estructuralista. Campos le quita a la obra el mote de caótica, pero desatiende algunos aspectos especulares y paródicos que no pertenecen, a su juicio, al núcleo central de la fábula, de acuerdo con los esquemas propuestos por Vladimir Propp. Por esta razón, en 1979, Gilda de Mello e Souza podrá decir que Campos

não percebeu [...] que a carta às Icamiabas desempenhava uma função importante na estrutura da obra; por isso tomou-a como um capítulo autônomo e ornamental, como pura exibição de virtuosismo lingüístico, quando era na verdade um comentário satírico da escolha desastrada do herói que acabava de preferir a portuguesa às filhas de Vei. ${ }^{21}$

De hecho el "aportuguesamiento" de Macunaíma comienza antes de endereçar la carta a las mujeres guerreras. Más tarde, en 1982, Eneida Maria de Souza, en una tesis dirigida por Julia Kristeva, y luego traducida y publicada en libro, jugando con las palabras concluye: "a perda da muiraquitã", es decir del amuleto, que sirve como leitmotiv, "serve de pano

18 LIMA, Jorge de. Dois Ensaios. Maceió: Casa Ramalho, 1929. p. 128.

19 PROENÇA, Manoel Cavalcanti. Roteiro de Macunaíma. Rio de Janeiro: Civilização Brasileira, 1969. p. 213-214. Para G. Freyre, el abismo entre la lengua escrita y la hablada era el resultado o traza del antagonismo entre el habla de los blancos de las casas-grandes y la de los negros de las senzalas.

20 Con respecto a la carta, véanse especialmente las páginas 187-189, del el capítulo VIII en CAMPOS, Haroldo de. Morfologia do Macunaima. São Paulo: Ed. Perspectiva, 1973.

21 SOUZA, Gilda de Mello e. O tupi e o alaúde: uma interpretação de Macunaíma. São Paulo: Duas Cidades, 1979. p. 52. 
de fundo para que se questione a sua função metalingüística, em que o discurso centrado na pedra se transforma em "conquista' da pedra preciosa do discurso" ${ }^{22}$. Palabras más, palabras menos, vuelve a insistir en el aspecto verbal y complaciente de la carta, aunque vea en ella más que el virtuosismo.

Para la edición crítica del libro, apoyada por la UNESCO, Maria Augusta Fonseca escribió un artículo dedicado exclusivamente a este texto polémico ${ }^{23}$. Ahí recuerda que la carta es - para el héroe - "a condensação escrita dos seus desejos carnais" ${ }^{24}$ y el arma retórica que éste tiene para pedir dinero. Tras esta contextualización y la insistencia en que "a língua é o próprio objeto do longo texto" 25 , M. A. Fonseca pasa a una propuesta interesante - en la línea de la interpretación "musical” de Mello e Souza: la carta sería análoga a un lundum, como representación del amor carnal y la danza que escenifica la conquista de la mujer por el hombre y viceversa. En un libro tan marcado por la sexualidad, así Mario de Andrade dijera que sus desnudos eran más castos que los de Gauguin ${ }^{26}$, es bastante importante este énfasis en la "rítmica discursiva"27, la composición del texto y las intenciones del remitente, en tanto aspectos que erotizan el discurso. Por último, y sin poder ser exhaustivos, se podría mencionar un ensayo de José Luiz Passos sobre los paralelos de la carta de Caminha al rey de Portugal y la de Macunaíma a sus "súbditas"; en ambas "o encontro com o Outro" serviría "como motivo e forma para a digressão epistolar", si bien - y esto es lo que plantea Passos -, la carta de 1926 implica "uma inversão carnavalizada do pro-

22 SOUZA, Eneida Maria de. A pedra mágica do discurso: jogo e linguagem em Macunaíma. Belo Horizonte: Ed. UFMG, 1988. p. 94.

23 El artículo de M. A. Fonseca se titula "A Carta pras Icamiabas" y se encuentra en la edición de Archivos citada (p. 278-294). Rescatamos unas pocas líneas de un texto que merecería ser comentado con más atención. M. A. Fonseca ha escrito con asiduidad sobre Macunaíma y es una interlocutora permanente de la obra andradiana.

24 ANDRADE, Mário de. Macunaíma: o herói sem nenhum caráter. Telê Porto Ancona Lopez (Coord.). Madrid: ALLCA XX / Ediciones UNESCO, 1988. p. 283. (Colección Archivos, vol. 6).

25 Ibid. p. 285.

26 Ibid. p. 425 .

27 Ibid. p. 293. 
jeto subjacente a formações discursivas como a de Caminha" ${ }^{28}$. El puente con la obra y los conceptos de Bajtín fue desarrollado de una manera rigurosa y original, en 1977, por el poeta y ensayista Mário Chamie, en un artículo que continúa vigente, aunque no suele ser muy citado ${ }^{29}$.

A estas opiniones se podrían sumar las del propio Andrade, que a medida que se vuelva a mirar el texto se podrán ir revisando. Como se ve la carta se ha vuelto un item privilegiado por la crítica, que ya no la quiere ver aislada del conjunto y que comprende sus intercambios, conexiones y resonancias. Por otro lado, la lectura presente, valiéndose de estos aportes, no puede sólo integrarlos o repetirlos. Por eso no volvemos sobre líneas que ya se han trabajado, aunque se podrían continuar (las analogías musicales, el despliegue y la diversidad lingüística, las deudas con los cronistas de Indias o los etnólogos extranjeros), sino que quisiéramos estudiar desde otra perspectiva el trasfondo colonial (o poscolonial, si se prefiere) del texto y pensar cuál es la importancia de la técnica que utilizó Mário de Andrade en esta carta, en contraste con el resto del libro, o al menos aquellas partes que tienen más deuda con un primitivismo característico de cuadros como los de Rousseau o Tarsila de Amaral. Porque en la "Carta pras icamiabas" hay una antropofagia de otro orden o de otro signo, diferente a la que rige la saga del héroe. Andrade lo señaló al decir, en la carta a Manuel Bandeira, ya citada por extenso, que el "estilo muda com [o] assunto" 30 , pero él mismo no parece haber captado hasta qué punto el cambio dependía no sólo de una dicotomía (selva / ciudad; mito / relación; Uraricuera ( São Paulo), sino de una manera de conciliar otras polari-

28 PASSOS, José Luiz. 0 espaço de mistura entre Pedro Vaz de Caminha e a "Carta pras Icamiabas". In: Ruinas de linhas puras: quatro ensaios em torno a Macunaíma. São Paulo: Annablume, 1998. p. 111 y 114.

29 Influido por Saussure, Greimas, Barthes, Hjelmslev, Kristeva y, en general, por las preocupaciones críticas que divulgaban ciertas revistas francesas estructuralistas, como Tel Quel, Mário Chamie publicó primero Intertexto: escrita rapsódica ensaio de leitura produtora. São Paulo: Praxis, 1970; y después, valiéndose de las funciones de la fábula, descritas por Propp (y simplificadas por Greimas), A transgressão do texto. Macunaína: linguagem dialógica. São Paulo: Praxis, 1972. De este último se desprendió, en parte, el ensayo Mário de Andrade: fato aberto e discurso carnavalesco. Revista Iberoamericana 98-99, 1977. p. 95-108.

30 ANDRADE, Mário de; BANDEIRA, Manuel. Correspondência. Marco Antonio de Moraes (Ed.). São Paulo: EDUSP/ IEB, 2000. p. 406. (Correspondência de Mário de Andrade). 
dades (lirismo / técnica; subconsciente / consciente; individuo / sociedad; ser / parecer) que su obra, como lo señaló Roberto Schwarz en $1961^{31}$, mantiene con frecuencia, a contrapelo de algunas críticas ocasionales y, podríamos hoy agregar, de partes o capítulos de sus propios textos creativos.

What emerges between mimesis and mimicry is a writing, a mode of representation, that marginalizes the monumentality of history, quite simply mocks its power to be a model, that power which supposedly makes it imitable.

Homi Bhabha, "Of Mimicry and Man"

La "epístola a las amazonas", que tal vez sería el título más justo si no fuera por una cierta ironía, es, a primera vista, una suerte de vademécum erótico, de catequismo a las súbditas vírgenes, que el héroe civilizador les dirige con fines didácticos que esconden su egoísmo o su penuria: el protagonista necesita "duzentas igaras cheias de bagos de cacau" ${ }^{2}$ para poder seguir frecuentando los burdeles de São Paulo - la “"zona estragada"'33 - , a la que prefiere referirse con eufemismos. La sátira, así vista, es en realidad brutal y sorprende que algunos críticos sigan insistiendo en la escenificación del lenguaje, en un capítulo que trasciende los latinismos y galicismos, los rodeos y los malabarismos verbales. Sin duda la acentuación, la pronunciación y la dicción se hacen arcaicas y, con frecuencia, aportuguesadas, y el héroe comete errores "crasos" - palabra a la cual recurre - como al usar "testículos" ${ }^{34}$ en vez de "versículos" (bíblicos); pero todos estos deslices y distorsiones acentúan lo absurdo de su megalomanía y de su apetito sexual. La carta no tiene realmente destinatarios, no podría ser leída por las icamiabas, pero tiene un texto entrelíneas, que descubre las intenciones del deseo y que se podría glosar así: mujeres

31 SCHWARZ, Roberto. 0 Psicologismo na poética de Mário de Andrade. In.: Sereia e o desconfiado: ensaios críticos. Rio de Janeiro: Paz e Terra, 2a ed., 1981.

32 ANDRADE, Mário de. Macunaíma: o herói sem nenhum caráter. Telê Porto Ancona Lopez (Coord.). Madrid: ALLCA XX / Ediciones UNESC0, 1988. p. 85. (Colección Archivos, vol. 6).

33 Ibid. p. 78.

34 Ibid. p. 85. 
amazonas, aprendan de las "francesas", o sea, las mujeres "fáciles" que venden su cuerpo ${ }^{35}$... En este mundo de ficción carnavalesca, el Emperador, que debe someter a la Reina para "triunfar", critica a sus súbditas por no rendirse pronto "nos braços de Orfeu, como se diz"36, y, por el contrario, luchar por su virginidad "no seqüestro inconseqüente em que viveis"37. Macunaíma proyecta pues una "série de milhoramentos" ${ }^{38} \mathrm{y}$ - aunque alerta a las súbditas sobre las mujeres de la noche paulista que, por sus melenas, parecen "éfebos e Antínous"39 - sugiere que, si ellas vivieran con esas mujeres y sin hombres, podrían asimilar los vicios que aprendieron "as companheiras da gentil declamadora Safô na ilha rósea de Lesbos" ${ }^{\text {" }}$. El humor no es del todo inocente y el proyecto aparentemente civilizador del bandeirante lujurioso queda puesto al descubierto y él, un poco en ridículo. Así, las contradicciones de la modernidad en Brasil se hacen visibles y, notoriamente, las de São Paulo como centro de otra periferia, pues ya no se presenta sólo a Brasil, con respecto a Portugal, sino a la Amazonía y al Nordeste con respecto a la gran ciudad ${ }^{41}$. Este anticlímax pone en entredicho la supuesta "ligereza" del libro y su aspecto meramente lúdico. En la totalidad del texto se manifiesta un

35 Conviene notar que las prostitutas no son brasileñas sino, según el estereotipo de la época, polacas o francesas, con lo cual Andrade evita entrar en “aguas pantanosas” y acentúa, una vez más, lo que hay de imitativo. También se puede observar que en un pasaje problemático - así haga eco de la estética antropófaga - el personaje recurre a un estereotipo para caracterizar a las mujeres de la calle y las tacha de lascivas y casi de burras: su "amável monstruosidade" consiste en "terem elas e cérebro nas parte pudendas” (ANDRADE, Mário de. Macunaíma: o herói sem nenhum caráter. Telê Porto Ancona Lopez (Coord.). Madrid: ALLCA XX / Ediciones UNESCO, 1988. p. 78 (Colección Archivos, vol. 6).). En este caso, la imagen carnavalesca se construye desde una óptica machista.

36 ANDRADE, Mário de. Macunaima: o herói sem nenhum caráter. Telê Porto Ancona Lopez (Coord.). Madrid: ALLCA XX / Ediciones UNESC0, 1988. p. 76. (Colección Archivos, vol. 6). Cf. la expresión "cair nos braços de Morfeu".

37 Ibid. p. 79.

38 Ibid. p. 79.

39 Ibid. p. 77.

40 Ibid. p. 79.

41 Sobre el rápido crecimiento de São Paulo y su importancia, son dicientes los artículos sobre “The Vargas Era” y “The Gold for São Paulo' Building”, en LEVINE, Robert M.; CROCITTI, John J.. The Brazil reader: history, culture, politics. Durham: Duke UP, 1999. 
doble empeño artístico e ideológico, como lo señaló Alfredo $\mathrm{Bosi}^{42}$, y esto lo hace mucho más que una pieza lúdica o un "brinquedo" 43 . No se olvide, por ejemplo, que la "Carta pras icamiabas" la firma "Macunaíma, Imperator" ${ }^{\text {", que juzga que }}$ sería más apropiado hablar del "Imperio da Mata Virgen", que del Mato Virgen, pues así, aunque esto quede implícito, la metáfora de la colonización y la penetración de la selva sería menos ambigua e, incluso, más abierta. Se trata de poblar el cuerpo virgen de la nación icamiaba y, por extensión, del Brasil, y a esta altura parece claro - y hay que decirlo - que el héroe "de nuestra gente" representa sólo una parte del país, y de manera parcial.

Pero la genialidad de la carta se advierte menos a través de estas observaciones de carácter ideológico, que gracias a la percepción de un hecho sencillo: todo el discurso grandilocuente y hegemónico del héroe constituye una farsa que asienta en la ambigüedad ${ }^{45}$. Si es cierto que éste, al proponer colonizar la virginidad del territorio, recuerda a Alencar y a los cronistas - y a otros creadores de foundational fictions -, no se puede olvidar que es precisamente a estos antecedentes - y a los bacheliers brasileños y a los literatos afrancesados de la época - que Macunaíma imita. La "Carta pras icamiabas" escenifica "a text rich in the traditions of trompe-l'œil, irony, mimicry and repetition", para decirlo con Homi Bhabha, texto que desafía y parodia "the epic intention of the civilizing mission" creando así "[an] area between mimicry and mockery, where the reforming, civilizing mission is threatened by the displacing gaze of its disciplinary double" ${ }^{" 46}$. En esta dirección cari-

42 Véase su ensayo "Situação de Macunaíma". In: ANDRADE, Mário de. Macunaima: o herói sem nenhum caráter. Telê Porto Ancona Lopez (Coord.). Madrid: ALLCA XX / Ediciones UNESCO, 1988. (Colección Archivos, vol. 6).

43 Así lo llamó el propio Andrade en un prólogo de 1926 que dejó inédito. Ver LOPEZ, Telê Porto Ancona. Macunaíma: a margem e o texto. São Paulo: HUCITEC, Secretaria de Cultura, Esportes e Turismo, 1974. p. 87. Ettore Finazzi-Agrò observa que "il 'brinquedo' assume le fatezze inevitabili dell'oggetto cultuale”. FINAZZI-AGRÒ, Ettore. La parola in gioco: la reinvenzione della memoria in Macunaíma, Rassegna Iberistica 33, 1998. p. 20.

44 ANDRADE, Mário de. op.cit. p. 85.

45 Mário de Andrade no parece darle el mismo peso a la sexualidad que aquí se señala, y enfatiza, por ejemplo, otros aspectos semánticos de la carta.

46 BHABHA, Homi. Of mimicry and man. The ambivalence of colonial discourse. In: The location of culture. London and New York: Routledge, 1994. p. 85-86. 
caturesca de la vida colonial y su falsa moral, es clave notar que un Emperador (en un país hasta hacía poco monárquico) es quien firma la misiva y que este documento aparentemente "administrativo" - que es menos una obra que un acto, y que al cine fue llevado como discurso - reproduce defectuosamente ciertas teorías coloniales o colonizadas. Por último, aunque no menos importante, conviene recordar al papagayo - imagen especular de toda la "rapsodia" - que de forma análoga al narrador, y también a Macunaíma, repite, según imaginamos, de manera deformada lo que oye, produciendo un efecto gracioso y ridiculizador. El papagayo es, en efecto, el mejor correlato objetivo de la idea de mímica - quizás más que de la de antropofagia - y encarna, además, varios símbolos. Ese pájaro exótico, que personifica al Brasil, evoca también a los colonizadores portugueses y sus mitos, a los piratas, a los viajes transatlánticos, a la selva selvaggia (Dante citado por Oswald de Andrade)... y por ello sirve de mediador, además de reproductor infiel de lo que retiene ${ }^{47}$. La "Carta pras icamiabas", que tiene un aspecto "chocante", pues imita un discurso de poder y presenta a un antihéroe ladino pidiendo dinero para brincar o retozar con las extranjeras, pone en evidencia algunas de las múltiples contradicciones de ese país de "perfeita ordem e progresso"48 que, con un sesgo positivista, decía luchar contra la supuesta degeneración nacional.

Dicho esto, vale la pena abrir un paréntesis. Las mayores contradicciones del propio Mário de Andrade pueden haber sido dos: no haberse distanciado lo suficiente de ese diagnóstico - que lo habrá llevado a subtitular su libro "o herói sem nenhum caráter"; y haber seguido una idea algo

47 "O aruaí, imitador da voz humana, encarna, ao mesmo tempo, uma voz que se fixa e emigra, imagem da escrita andradina que consiste, justamente, na arte de passear de um signo a outro, disseminando-os e propiciando a migração infinita de sentidos”. (SOUZA, Eneida Maria de. A pedra mágica do discurso: jogo e linguagem em Macunaíma. Belo Horizonte: Ed. UFMG, 1988. p. 123). Cf. el ensayo de Raul Antelo, "Macunaíma: Aproriação e Originalidade", incluido en la edición crítica de la Colección Archivos (pp. 255-265). Por su parte, Kimberle López (LÓPEZ, Kimberle S. Modernismo and the ambivalence of the postcolonial experience: cannibalism, primitivism, and exoticism Mário de Andrade's Macunaíma. Luso-Brazilian Review 35, 1, 1998. p. 34.) ve en el papagayo la idea de transculturación que discute Mary Luoise Pratt, en Imperial Eyes, donde el discurso colonial es apropiado por el colonizado y devuelto a la metrópolis.

48 ANDRADE, Mário de. Macunaima: o herói sem nenhum caráter. Telê Porto Ancona Lopez (Coord.). Madrid: ALLCA XX / Ediciones UNESCO, 1988. p. 82. (Colección Archivos, vol. 6). 
esencialista - por más subversiva que sea la antropofagia - de lo que podría definir un carácter nacional. Andrade denuncia la ausencia de ese carácter o rasgo definitorio del brasileño y, al hacerlo, de cierta manera acepta su validez. "0 brasileiro não tem caráter porque não possui nem civilização nem consciência tradicional [...] Dessa falta de caráter psicológico creio otimistamente, deriva a nossa falta de caráter moral”. Así se expresa en el prólogo que dejó sin publicar ${ }^{49} \mathrm{y}$ da a entender que una lectura de la "Carta pras icamiabas" sería tal vez poco transgresora: al héroe le faltaría carácter por el mismo hecho de estar expresándose de manera artificial, o mejor, artificiosa, y practicar, así, a malandragem ${ }^{50}$.

Todo esto puede llevar a una nueva reflexión. Alfredo Bosi escribió que sería inadecuado hablar de la construcción de una persona en Macunaíma, pues Mário de Andrade habría intentado mantenerse fiel al modo de construcción de los héroes de la mitología amazónica, "acionados direta e prementemente pelos estímulos do prazer ou do medo" y debido a una "irresolução cognitiva e afetiva" ${ }^{51}$ que lo habría caracterizado durante su vida. De ninguna de las dos afirmaciones podemos estar seguros; conviene recordar, además, que Andrade afirma constantemente un interés por el cambio de estilos y perspectivas narrativas. Por ello, y tras haber hablado de imitación, de antropofagia y de parodia, sí nos parece adecuado hablar de la construcción de una persona.

Roberto Schwarz señaló que "the Antropófagos - like the nacionalists - take as their subject the abstract Brazilian"52; y Roberto Reis agregó que: "22 ainda não é o retrato do Brasil,

49 En LOPEZ, Telê Porto Ancona. Macunaíma: a margem e o texto. São Paulo: HUCITEC, Secretaria de Cultura, Esportes e Turismo, 1974. p. 87-88.

50 En "Puffy, ugly, slothful and inert": degeneration in brazilian social thought, 1880-1840, Dain Borges (BORGES, Dain. "Puffy, ugly, slothful and inert": degeneration in brazilian social thought, 1880-1840, Journal of Latin American Studies 25, 2 1993. p. 240.) muestra como "the rethoric of degeneration [...] turned into the central, near official ideology of the conservative, oligarchical Republic (1889-1930)", y advierte que la pereza era uno de los temas dominantes de esta ideología. Por otro lado, la "homologia entre a estética de Mário e a experiência acumulada de uma classe", fue ya abordada por Carlos Eduardo Berriel en una tesis de maestría. Ver SCHWARZ, Roberto. Que horas são? Ensaios. São Paulo: Companhia das Letras, 1987.

51 ANDRADE, Mário de. Macunaíma: o herói sem nenhum caráter. Telê Porto Ancona Lopez (Coord.). Madrid: ALLCA XX / Ediciones UNESCO, 1988. p. 179. (Colección Archivos, vol. 6).

52 SCHWARZ, Roberto. Essays on brazilian culture. Londres: Verso, 1992. p. 9. 
mas a sua mistificação"53. A estos juicios tan tajantes habría que oponer quizás, pese a sus ambivalencias, la "Carta pras icamiabas”. Porque en ella sí hay un retrato, así no sea optimista, y el sujeto es menos ese brasileño desregionalizado de la ficción mítica, que el paulista pedante que quiere escribir como la moda considera elegante y, que al hacerlo, sublima sus deseos y busca alcanzar sus objetivos menos nobles: una recompensa o unas albricias. La burla literaria recuerda las de Rabelais, por ejemplo, contra los jóvenes estudiantes que hablan de manera latinizada, y ofrece la paradoja de una metamorfosis moral y psicológica $^{54}$. Hay pues que distinguir lo que Cavalcanti Proença llamó "hipodigma"55 - una especie de "suma-sintesis" 56 , que se aplicaría al Macunaíma salvaje, por así decir, o al personaje total -, de la "máscara lingüística" asumida por el protagonista en el capítulo IX, que es mucho más específica y paródica. En la carta, Macunaíma no es sino una representación parcial, irónica y adulterada del brasileño letrado. Este doble movimiento de identificación y rechazo, de parecido y diferencia, de imitación y deformación, se asemeja a un escenario colonial de amenaza potencial, en el cual "the twin figures of narcissism and paranoia" "repeat furiously, uncontrollably" 57 . En la carta sí hay el esbozo de un personaje, de una máscara, y lo que puede dar la sensación de una cierta "irresolución" 58 no es tanto la sobreposición de rasgos, sino más bien la ambigüedad, es decir, el hecho de que Macunaíma se mantenga tupi cuando intenta no serlo (not

53 REIS, Roberto. Passando a limpo. Ideologies and literature 2, 1, 1987. p. 138.

54 La metamorfosis que en otro texto habría podido permitir la creación de dos personajes diferentes (el “tupi” y el "no-tupi”, Saladin Chamcha y Gibreel Farishta), en Macunaíma es asumido por uno sólo.

55 “0 herói é o que se chama, em Zoologia, um hipodigma. Não tem existência real. É um tipo imaginário no qual estão contidos todos os caracteres encontrados nos indivíduos da espécie até então conhecidos" (PROENÇA, Manoel Cavalcanti. Roteiro de Macunaíma. Rio de Janeiro: Civilização Brasileira, 1969. p. 15). Menos acertada resulta la apreciación de Eneida Maria de Souza, si nos atenemos al análisis de la carta: "A construção de uma nova visão de cultura brasileira", escribe, refiriéndose a Mário de Andrade, "se fundamenta no artefato simbólico de uma linguagem sem nenhum caráter, no amálgama de estilos e apropriações das mais diversas fontes do sabor erudito e popular". SOUZA, Eneida Maria de. Preguiça e saber. Revista de Letras 33, 1993. p. 83.

56 Utilizamos una expresión del Ultimatum de Álvaro de Campos.

57 BHABHA, Homi. Of mimicry and man. The ambivalence of colonial discourse. In.: The location of culture. London and New York: Routledge, 1994. p. 91.

58 BOSI. Ver supra, nota 42. 
to be tupi). De hecho, el héroe imita "a tão preciosa quão solene língua dos colaboradores da Revista de Língua Portuguesa”, y aprovecha un verso de Camões ${ }^{59}$ y frases "de Rui Barbosa, de Mário Barreto, [e] dos cronistas portugueses coloniais" ${ }^{\text {, }}$, pero lo hace parcialmente, como un papagayo que, al repetir un sonido, no puede evitar su distorsión.

Si por un lado Macunaima es un avance sobre las narrativas preocupadas por definir tipologías nacionales (Domingo Sarmiento, Euclides da Cunha, Rómulo Gallegos...), por otra parte se encuentra en el impasse de cómo definir al héroe o antihéroe, sin caer en los estereotipos de inspiración romántica. En este contexto, la carta se podría ver como un intento de solución parcial. En ella la idea de repetición y variación continua que informaría el relato, según la analogía musical, sirve para crear una máscara, producir una deformación y unos efectos satíricos y ya no para alargar una aparente - y sólo aparente - enumeración caótica. El preciosismo nativista cede su lugar al lenguaje requintado; la antropofagia a la idea de imitación, ya no sólo como técnica de composición, sino como realidad histórica y medio retórico de alcanzar ciertos fines pragmáticos. Sin duda esta faceta del héroe mutable es sólo una ficção de interludio, pero aquí hay una diferencia formal en relación con los demás capítulos. No es por presencia y acumulación que se construye el paisaje o la narración; es más bien por ausencia y uso de pequeños detalles - como en una novela más que en un mito - que se desenvuelve el relato epistolar. Se podría pensar, pues, que el bricolage, como lo entiende LéviStrauss, tendría para el escritor un mayor alcance en el plano del lenguaje y sus diversos efectos, que en el - menos genérico - de la creación de unos personajes ${ }^{61}$. Al menos si lo que se

59 Como indica Maria Augusta Fonseca en su ensayo (sección "Mitos e Monstros”). Ver ANDRADE, Mário de. Macunaima: o herói sem nenhum caráter. Telê Porto Ancona Lopez (Coord.). Madrid: ALLCA XX / Ediciones UNESCO, 1988. (Colección Archivos, vol. 6).

60 ANDRADE, Mário de. Taxi e crônicas no Diário Nacional. Telê Porto Ancona Lopez (Ed.). São Paulo: Duas Cidades / Secretaria de Cultura, Ciência e Tecnologia, 1976. p. 434.

61 Aquí sigo la idea de Roberto Schwarz sobre el momento en que Mário de Andrade habría encontrado una solución provisional a las dicotomías antes mencionadas (lirismo / técnica, subconsciente / consciente, individuo / sociedad, ser / parecer), al relacionar la libertad del personaje con una "poética profunda", y no sólo con una especie de orientación intuitiva. Ver SCHWARZ, Roberto. Sereia e o desconfiado: ensaios críticos. Rio de Janeiro: Paz e Terra, 2a ed., 1981. p. 23. 
pretende es que tengan una cierta independencia y credibilidad histórica. Andrade utilizó en Macunaíma los "mitos y leyendas" de la segunda parte de la obra clásica de Koch-Grünberg, Vom Roroima zum Orinoco $^{62}$, y extrajo de ella al héroe pícaro y brincalhão, pero al contrario de lo que se ha dicho, lo amoldó a su propia visión literaria. Es la mirada de Andrade, más que la del informante del etnólogo alemán, la que triunfa y permite ver a ese personaje que Alfredo Bosi, con sorpresa (pues es un héroe da nossa gente), describía como "cúpido, lascivo, glutão, indolente, covarde, mentiroso" ${ }^{\text {". }}$. Las leyendas recogidas por Koch-Grünberg no son tan elocuentes y en Macunaima vemos exacerbados ciertos rasgos. Ahora, en la carta del Imperator, que parodia al héroe civilizador, Andrade aprovechó su propia experiencia urbana y colocó al protagonista en un escenario colonial que no estaba en las leyendas, haciéndolo vestir - mal vestido - con el traje paternalista de un "redentor de la patria". De este capítulo se habría podido desprender - y en parte lo hace - un nuevo actor, menos indolente, pero, tal vez, más contradictorio y autoritario. (Actor al cual le faltó llevar a cabo su proyecto, esto es, viajar a Europa, que constituye una segunda parte del libro que nunca fue escrita).

En suma: la parodia del poder, de sus protagonistas, móviles y principios, es clave para comprender la "Carta pras Icamiabas", que imita un discurso de poder y deja traslucir su carácter imitativo. En ella no se intenta una antropofagia global, que ofrecería una visión muy abstracta de Brasil y de los diferentes "cuerpos" sociales, históricos, sexuales, etc.; al contrario, la carta remite sobre todo - aunque no exclusivamente - a un lugar (São Paulo) y a un momento (el principio del siglo XX), e intenta presentar una imagen todavía híbrida, aunque más definida, de un personaje consciente y provocadoramente transfigurado, que representa a una cierta clase alfabetizada y ansiosa de ascenso. Andrade buscaba imitar no

62 He consultado la lujosa edición venezolana de la obra de Koch-Grünberg, Del Roraima al Orinoco. Sobre las icamiabas hay un curioso libro publicado en Porto Alegre en 1937, que aunque no cita a Koch-Grünberg ni a Mário de Andrade, cita a Barbosa Rodrigues (O Muiraquitã, 1889) y a Raimundo Morais (Na Planicie Amazônica, 1926), entre otros, y muestra hasta qué punto el mito de las icamiabas seguía siendo materia de estudio y especulación. Véase GUID0, Angelo. $O$ reino das mulheres sem lei: estudos de mitologia amazônica. Porto Alegre: Liv. do Globo, 1937.

63 ANDRADE, Mário de. Macunaíma: o herói sem nenhum caráter. Telê Porto Ancona Lopez (Coord.). Madrid: ALLCA XX / Ediciones UNESCO, 1988. p. 178. (Colección Archivos, vol. 6). 
tanto las narraciones legendarias y las enumeraciones casi indefinidas - que aprovecharía también Guimarães Rosa -, como un discurso pretencioso, revelador de la nueva máscara social del protagonista, ahora supuesto emperador. Por eso la burla es doble: por una parte del discurso y, por otra, de la figura que lo repite con dificultad - ese monarca que de manera ambigua representa los restos de un colonialismo decadente.

Dejando de lado una posible preocupación estructuralista, que se preguntaría cómo encajar la carta dentro de la unidad o la totalidad del texto, resulta posible revalorar la singularidad de la carta y ver cómo ella renueva y dinamiza las constantes sátiras de la obra. Sin duda la crónica escrita del héroe corta la "continuità caratteristica fra phone e logos" "64 que refuerza la imagen de un mito. Y la interrumpe en un libro-rapsodia, narrado por un yo-juglar, que oye o recobra la historia que renueva un portavoz-papagayo ${ }^{65}$. Con todo, esta ruptura con la tradición épica, que abre una zanja en esa "oral epic that emphasizes the extra-European origins of Brazilian reality"66, es relativa. Finalmente, la carta es la otra cara de la medalla de la narración y de la historia que prima en el libro; es un momento de la inversión carnavalesca de Macunaíma, esto es, parte de un proceso total de entronización y desentronización.

Como se podrá recordar, a lo largo del texto el héroe casi muere pero revive, es celebrado y vapuleado, es conquistador y también conquistado, es rey tanto como esclavo, es explotador y luego explotado, es el que desea a las francesas y después el que se transforma en francesa, es, en fin, el vencedor y el vencido, el engatusador y el engatusado. Estas transformaciones explican el carácter cómico del personaje y su cambio sucesivo de máscaras. Macunaíma está permanentemente subiendo y bajando en la escala (social, política, económica o sexual) y es el emperador que "num primeiro momento, ganha o Reino; num segundo, o perde; e, num terceiro, o ganha de novo para

64 FINAZZI-AGRÒ, Ettore. La parola in gioco: la reinvenzione della memoria in Macunaíma. Rassegna Iberistica 33, 1998. p. 21.

65 Ave, de resto, no adánica, que representa en el texto la polifonía. (Y que sólo por analogía recuerda la jandaia una especie de perico, que vuelve a aparecer al final de Iracema.)

66 GEORGE, David. Macunaima, a parody of The Lusiads. Chasqui 16, 1, 1984. p. 42. 
ser, num quarto e derradeiro, destituído pela lenda do mal humano". La observación es de Mário Chamie ${ }^{67}$, que registra cómo Macunaíma domina y posee a Ci, la Mãe-do-Mato; luego entra a São Paulo y lo abandona el cortejo de aves; después recupera la muiraquitã; y por último, en su regreso a la selva (y de nuevo seguido por las aves) encuentra a Uiara, que le tiende una trampa erótica y fatal.

En este contexto, la carta representa un momento de entronización falsa (o calculada) de Macunaíma, que ha sido explotado al entrar a la ciudad, donde cambia las piezas de cacao que traía, y que ahora, en contrapartida, debe solicitar más cacao a sus "súbditas" y actuar como emperador. Como se sabe, al hacerlo imita mal el discurso aportuguesado de los paulistas, recurriendo así a una máscara de tercer orden: la del sujeto colonizado que representa a una figura imperial. La parodia es completa y la extrañeza que producen las distorsiones es total, ya que el emperador imita otra imitación. Evoca a los cronistas, pero lo hace a través de la lengua escrita de los capitalinos, que tiene trazas del imperio, pero que no es el Imperio (aunque pueda ser imperial...) ni es enunciada desde la metrópolis. El proceso de entronización desde la periferia y el lugar donde se prepara la desentronización, el carnaval, surgen así como un medio y un espacio idóneos para representar estas múltiples ambivalencias y señalar, al mismo tiempo, las intrincadas y complejas relaciones de poder.

La entronización de Macunaíma en rey-emperador y su "desdoblamiento" en un pretendido héroe civilizador y falso letrado, son dos caras de un mismo movimiento con intención paródica y carnavalizadora. Así como sensualidad y metamorfosis llegan a ser equivalentes, también la degradación y exaltación del héroe sin ningún carácter van de la mano con la parodia de cada una de sus máscaras - y, en el caso de la carta, de sus estilos, efectos y formas lingüísticas. En ambos casos - ridendo castigat mores - se puede reconocer el carácter crítico del modernismo y rebatir la lectura demasiado "mítica" de Macunaima ${ }^{68}$. La "carta pras icamiabas" ratifica la posibi-

67 CHAMIE, Mário. Mário de Andrade: fato aberto e discurso carnavalesco. Revista Iberoamericana 98-99, 1977. p. 106.

68 Ver por ejemplo esta acotación de Rodríguez Monegal: “Mário de Andrade saltaba por encima de las convenciones del realismo y se instalaba en pleno mito”. RODRÍGUEZ MONEGAL, Emir. Anacronismos: Mário de Andrade y Guimarães Rosa en el contexto de la novela hispanoamericana. Revista Iberoamericana 98-99, 1977. p. 110. 
lidad de leer el texto de otra manera, desde diversas perspectivas - lúdica, teatral y paródica, entre otras - y, no apenas, como reelaboración de unos mitos y leyendas, recreados a partir de una técnica trovadoresca. Más allá del virtuosismo y de las glosas etnográficas, el "libro escrito en un período de descanso" (iy supuestamente en una hamaca!) ofrece mucho más que un divertimento y permite captar, a la vez, un distanciamiento crítico, implícito en la parodia, y un fraccionamiento socio-lingüístico, pues no todos los brasileños tendían a letrados. Por ello es paradójico que un libro que casi hubiera podido leerse como una novela de tesis - por el título (sem nenhum caráter) - no haya suscitado más reflexiones extraliterarias. La carta, en esta medida, por su posicionamiento, su diferencia y su técnica, nos invita a seguir buscando otros textos contemporáneos similares, y a reevaluar los aportes de la vanguardia. En el caso brasileño, la novela neorrealista minimizó estos aportes; pero hoy convendría comenzar a reconocerlos, pues también tuvieron significado y alcance.

Fin / Tem mais não 